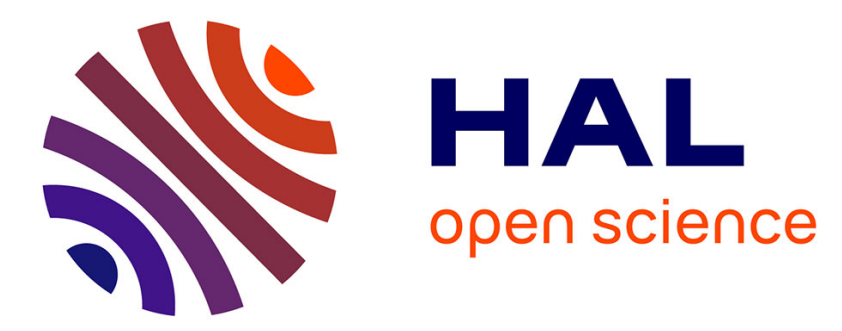

\title{
Comparative Study of Gaussian Dispersion Formulas within the Polyphemus Platform: Evaluation with Prairie Grass and Kincaid Experiments
}

\author{
Irène Korsakissok, Vivien Mallet
}

\section{- To cite this version:}

Irène Korsakissok, Vivien Mallet. Comparative Study of Gaussian Dispersion Formulas within the Polyphemus Platform: Evaluation with Prairie Grass and Kincaid Experiments. Journal of Applied Meteorology and Climatology, 2009, 48 (12), pp.2459-2473. 10.1175/2009JAMC2160.1 . inria00566228

\section{HAL Id: inria-00566228 \\ https://hal.inria.fr/inria-00566228}

Submitted on 4 Mar 2011

HAL is a multi-disciplinary open access archive for the deposit and dissemination of scientific research documents, whether they are published or not. The documents may come from teaching and research institutions in France or abroad, or from public or private research centers.
L'archive ouverte pluridisciplinaire HAL, est destinée au dépôt et à la diffusion de documents scientifiques de niveau recherche, publiés ou non, émanant des établissements d'enseignement et de recherche français ou étrangers, des laboratoires publics ou privés. 


\title{
Comparative study of Gaussian dispersion
}

\author{
formulae within the Polyphemus platform:
}

\section{evaluation with Prairie Grass and Kincaid}

\section{experiments.}

\author{
IRÈNE KORSAKISSOK * \\ CEREA, Joint Research Laboratory, ENPC / EDF R\&D, Université Paris Est \\ Vivien Mallet
}

INRIA

${ }^{*}$ Corresponding author address: CEREA, 6-8 avenue Blaise Pascal, Cité Descartes, 77455 Champs-surMarne, Marne la Vallée Cedex 2 , France.

E-mail: korsakissok@cerea.enpc.fr Tel: 33(0)164152168 


\begin{abstract}
This paper details a number of existing formulations used in Gaussian models in a clear and usable way, and provides a comparison within a single framework - the Gaussian plume and puff models of the air quality modeling system Polyphemus. The emphasis is made on the comparison between (1) the parameterizations to compute the standard deviations and (2) the plume rise schemes. The Gaussian formulae are first described and theoretically compared. Their evaluation is then ensured by comparison to the observations as well as to several well-known Gaussian and CFD models performance. The model results compare well with the other Gaussian models for two of the three parameterizations for standard deviations, Briggs's and similarity-theory, while Doury's shows a tendency to underestimate the concentrations because of a large horizontal spread. The results with Kincaid experiment point out the sensitivity to the plume rise scheme and the importance of an accurate modeling of the plume interactions with the inversion layer. Using three parameterizations for the standard deviations and the same number of plume rise schemes, we were able to highlight a large variability in the model outputs.
\end{abstract}

\title{
1. Introduction
}

Gaussian models are widely used to model dispersion at local scale, in spite of their wellknown limits, since they are based on simple analytical formulae, and computationally cheap to use. However, the use of empirical schemes to compute the Gaussian standard deviations involves large uncertainties - hence many different formulations exist. When plume rise occurs, additional parameterizations are introduced, which results in still more variability. In 
this paper, the Gaussian models developed on the Polyphemus platform (Mallet et al. 2007) are used to evaluate the results sensitivity to the physical parameterizations for standard deviations and plume rise. This evaluation is ensured by means of theoretical study, comparison to experimental data, and comparison to other well-known Gaussian models performance, like US EPA models ISCST3 and AERMOD, and UK's widely used Gaussian model ADMS. Since Polyphemus is not a single air quality model but a platform aimed at handling different models, it provides an appropriate framework to benchmark parameterizations and features

of Gaussian models, thus evaluating the spread in model outputs. In addition, one of the aims of this paper is also to put together a number of different parameterizations that were previously described in many different contexts, in a clear and usable way, which also makes comparisons easier.

We first present the Polyphemus Gaussian models in Section 2, with an emphasis on the parameterizations for standard deviations and plume rise. A first comparison of the parameterizations is given in Section 3. Then, the model evaluation is carried out with Prairie Grass (Section 4) and Kincaid (Section 5) field-experiments datasets.

\section{Description of the Polyphemus Gaussian models}

a. The Gaussian plume and puff models

Polyphemus hosts both a Gaussian plume model and a Gaussian puff model. Arya (1999) reviews the main assumptions for the relevance of the two models. A Gaussian plume model assumes a Gaussian distribution of mean concentration in the horizontal (crosswind) and 
vertical directions, in steady-state and homogeneous meteorological conditions. The dispersion in the downwind direction is supposed to be negligible compared to the transport by the mean wind in the plume model. A Gaussian puff model discretizes the plume into a series of puffs, each of them having a Gaussian shape in all three directions. The puff model can also take into account different meteorological data for each puff, therefore allowing a more accurate simulation of non-stationary and non-homogeneous conditions. In Polyphemus, the plume and puff models share the same parameterizations. Thus, in stationary and homogeneous conditions - as assumed in the Prairie Grass and Kincaid experiments - the Gaussian puff model gives the same solution as the Gaussian plume model, if averaged over a long enough period. Henceforth, only the Gaussian plume model is therefore used (it was verified that the Gaussian puff model gave the same results).

For a stationary plume, the concentration $C$ is given by the Gaussian plume formula:

$$
C(x, y, z)=\frac{Q}{2 \pi \sigma_{y} \sigma_{z} \bar{u}} \exp \left(-\frac{\left(y-y_{s}\right)^{2}}{2 \sigma_{y}^{2}}\right) \times\left[\exp \left(-\frac{\left(z-z_{p}\right)^{2}}{2 \sigma_{z}^{2}}\right)+\exp \left(-\frac{\left(z+z_{p}\right)^{2}}{2 \sigma_{z}^{2}}\right)\right]
$$

$Q$ is the source emission rate, given in mass per second, $\bar{u}$ is the mean wind velocity, and $\sigma_{y}$ and $\sigma_{z}$ are the Gaussian plume standard deviations in the horizontal (crosswind) and vertical directions. The coordinate $y$ refers to the crosswind horizontal direction, and $y_{s}$ is the source coordinate in that direction. The coordinate $z$ refers to the vertical coordinate and $z_{p}$ is the plume height above ground - sum of the source height and the plume rise (see Section c). The second term of the last factor represents the ground reflection; similarly, additional terms can take into account the reflections on the elevated inversion layer. Also, when the plume is mixed enough in the boundary layer $\left(\sigma_{z}>1.5 z_{i}\right)$, the formula is modified to consider that the plume is vertically homogeneous. In addition, other factors can be 
applied to this formula in order to take loss processes into account, such as dry deposition, scavenging, radioactive or biological decay. In Polyphemus, full gaseous chemistry may also be handled by the Gaussian puff model.

\section{b. Dispersion parameterization schemes}

The expression of the total plume standard deviation is the sum of the spread due to

turbulence $\left(\sigma_{y_{\mathrm{turb}}}, \sigma_{z_{\mathrm{turb}}}\right)$, the additional spread due to plume rise $\left(\sigma_{y_{\mathrm{pr}}}, \sigma_{z_{\mathrm{pr}}}\right)$, and the initial spread due to the diameter $d_{s}$ of the source:

$$
\sigma_{y}^{2}=\sigma_{y_{\mathrm{turb}}}^{2}+\sigma_{y_{\mathrm{pr}}}^{2}+d_{s}^{2} / 4, \quad \sigma_{z}^{2}=\sigma_{z_{\mathrm{turb}}}^{2}+\sigma_{z_{\mathrm{pr}}}^{2}
$$

For the sake of clarity, $\sigma_{y_{\mathrm{turb}}}$ and $\sigma_{z_{\mathrm{turb}}}$ are named in this section $\sigma_{y}$ and $\sigma_{z}$. These standard deviations are estimated through empirical schemes, as functions of the downwind distance to the source and the stability, based on a few dispersion field experiments. Here, three parameterizations are described. Two of them are based on a discrete description of the atmospheric boundary layer: the Briggs formulae and the Doury formulae. The third one is based on similarity theory, and involves parameters such as the wind velocity fluctuations, the Monin-Obukhov length, the mixing height and the friction velocity.

\section{1) Briggs's FORMUlae}

The Briggs formulae are based on the Pasquill-Turner stability classes (Turner 1969) and fitted on the Prairie Grass experiment. This parameterization is born from an attempt to synthesize several widely used schemes by interpolating them for open country and for urban 
areas, for which they are particularly recommended. The full formulae can be found in Arya (1999) for instance. The general form is given by:

$$
\sigma_{y}=\frac{\alpha x}{\sqrt{1+\beta x}}, \quad \sigma_{z}=\alpha x(1+\beta x)^{\gamma}
$$

with $x$ the downwind distance from source, and $\alpha, \beta$ and $\gamma$ coefficients depending on Pasquill stability class. There are six stability classes corresponding to different states of the atmosphere (Pasquill 1961), from A (extremely unstable) to F (stable).

\section{2) Doury's Formulae}

An alternative parameterization is described in Doury (1976). This parameterization has been developed for the specific application of radionuclide dispersion, and fitted on a wider experimental field than the Prairie Grass field. The formulae use only two stability situations, corresponding to "normal" and "low" dispersion, determined by the vertical temperature gradient. By default, it is assumed that low dispersion occurs during nighttime with low

wind speed $\left(u \leq 3 \mathrm{~ms}^{-1}\right)$. The standard deviations are given in both cases in the general form:

$$
\sigma_{y}=\left(A_{h} t\right)^{K_{h}}, \quad \sigma_{z}=\left(A_{z} t\right)^{K_{z}}
$$

where $t$ is the transfer time since release time. In the case of a steady-state plume, $t=x / u$, where $x$ is the distance from the source and $u$ is the wind speed. The formulae for the normal situation can be found in Demaël and Carissimo (2008). 


\section{3) Similarity THEORY}

If enough meteorological data is available, $\sigma_{y}$ and $\sigma_{z}$ can be estimated using the standard deviations of wind velocity fluctuations in crosswind horizontal direction $\sigma_{v}$ and in vertical direction $\sigma_{w}$. Following Irwin (1979), dispersion coefficients are investigated in the form:

$$
\sigma_{y}=\sigma_{v} t F_{y}, \quad \sigma_{z}=\sigma_{w} t F_{z}
$$

where $t$ is the time in seconds, and $F_{y}$ and $F_{z}$ are functions of a set of parameters that specify the characteristics of the atmospheric boundary layer. These functions are determined from experimental data. Various expressions of $F_{y}$ and $F_{z}$ have been proposed (e.g., Irwin (1979), Weil (1988)). Appendix 7 details the formulations used in Polyphemus for $F_{y}, F_{z}, \sigma_{v}$ and $\sigma_{w}$. A modified formulation from Hanna and Paine (1989) is also available for the case of

elevated sources (above $100 \mathrm{~m}$ height). Two different formulations are also given for the standard deviations above the boundary layer.

\section{c. Plume rise schemes}

When emissions are hotter than the ambient air, or have a significant ejection speed, the plume generally reaches a certain height before behaving like the surrounding air: this difference in heights can be significant (up to a few hundreds of meters) and is called "plume rise" (see Figure 1). Estimates of the plume rise can be provided, based on the source initial height, diameter, ejection temperature and ejection velocity. In all formulae described below, it is assumed that the plume instantaneously reaches its final height at the emission time, then travels downwind. More accurate formulations allow to determine the plume rise as a 
function of the downwind distance, but are not investigated here.

If the plume rise is $\Delta h$, the plume final height is given by $z_{p}=z_{s}+\Delta h$, with $z_{s}$ the source height. The initial spread due to plume rise is added to the total standard deviations at the emission time according to Equation 2. It is estimated following Irwin (1979) for the crosswind spread and Hanna and Paine (1989) for the vertical spread:

$$
\sigma_{y_{\mathrm{pr}}}=\Delta h / 3.5, \quad \sigma_{z_{\mathrm{pr}}}=\Delta h / 2
$$

Three different formulae to compute plume rise are described in this section. While the Briggs-HPDM formulae depend on the stability of the atmosphere, the two other formulae depend only on the source dynamics and buoyancy and are based on the source heat rate.

\section{1) BRIGgS-HPDM PLUME RISE}

The plume rise computation is based on the Briggs formulae - detailed in Seinfeld and Pandis (1998) — assuming a buoyancy-driven plume rise (Equations 8 to 12) . In the formulae, $\Delta h$ is the plume rise, $u$ is the wind velocity, $w_{*}$ is the convective velocity and $u_{*}$ is the friction velocity. In addition, $s_{p}$ is the Briggs static stability parameter and $F_{b}$ is the initial buoyancy flux parameter. They are defined as:

$$
s_{p}=\frac{g \mathrm{~d} \theta / \mathrm{dz}}{T}, \quad F_{b}=g v_{s} d_{s}^{2} \frac{T_{s}-T}{T_{s}}
$$

with $g$ the gravity acceleration, $\mathrm{d} \theta / \mathrm{dz}$ the vertical gradient of potential temperature, $T$ the ambient temperature, $v_{s}$ the vertical velocity of the emission, $d_{s}$ the source diameter and $T_{s}$ the source temperature. 
(i) Stable cases

The formulae for stable cases come from Seinfeld and Pandis (1998) and are also used in the HPDM model (Hanna and Paine 1989). The final plume rise is $\Delta h=\min \left(\Delta h_{1}, \Delta h_{2}\right)$.

$$
\Delta h_{1}=2.6\left(\frac{F_{b}}{u s_{p}}\right)^{1 / 3}, \quad \Delta h_{2}=4 F_{b}^{1 / 4} s_{p}^{-3 / 8}
$$

(ii) Unstable and neutral cases

The following formulae come from Seinfeld and Pandis (1998) and are originally from Briggs.

$$
\begin{aligned}
& \Delta h=21.4 \frac{F_{b}^{3 / 4}}{u} \quad \text { if } F_{b}<55 \\
& \Delta h=38.71 \frac{F_{b}^{3 / 5}}{u} \quad \text { if } F_{b} \geq 55
\end{aligned}
$$

In the above formulae, ambient turbulence is supposed to be negligible, compared to the plume internal turbulence. However, in many unstable and neutral cases, the plume eventually reaches a point where ambient turbulence is large enough to stop the plume vertical progress. In Briggs (1971), this so-called "breakup" height is determined as the point where both the plume and the ambient eddy dissipation rates are equal. It is reported in Hanna (1984) and used here for neutral cases, whereas the unstable breakup formula comes from Hanna and Paine (1989). When there is the choice between a breakup formula and a Briggs formula, the one giving the minimal plume rise is chosen.

$$
\begin{aligned}
& \Delta h=4.3\left(\frac{F_{b}}{u w_{*}^{2}}\right)^{3 / 5} z_{i}^{2 / 5} \text { unstable } \\
& \Delta h=1.54\left(\frac{F_{b}}{u u_{*}^{2}}\right)^{2 / 3} z_{s}^{1 / 3} \text { neutral }
\end{aligned}
$$




\section{2) Holland FORMula}

This plume rise formula is the same for all stabilities. It comes originally from Holland (1953) and was modified by Stümke (1963).

$$
\Delta h=1.5 \frac{d_{s} v_{s}}{u}+65 \frac{d_{s}^{1.5}}{u}\left(\frac{T_{s}-T}{T_{s}}\right)^{1 / 4}
$$

\section{3) Concawe Formula}

In Brummage (1968), a comparison study was made between several plume rise formulae, including the Holland-Stümke formula which was among the best. An attempt was made to synthesize the multiple formulations into a relationship in the form $\Delta h=K \frac{Q_{h}^{\alpha}}{u^{\beta}}$, where $Q_{h}$ is the source heat rate and $K, \alpha$ and $\beta$ are empirical constants. It resulted in the Concawe formulae:

$$
\Delta h=0.071 \frac{Q_{h}^{0.55}}{u^{0.67}}
$$

Here, the ejection heat rate is computed using the source diameter, its ejection velocity and the temperature difference between the plume and ambient air:

$$
Q_{h}=228.19 v_{s} d_{s}^{2}\left(T_{s}-T\right)
$$

This is an approximation, based on the assumption that the calorific capacity of the ejected gas is not too different from that of air. 


\section{4) Partial penetration in the inVERsion Layer}

In the case of an elevated source with a large plume rise, the plume can partially or totally penetrate the inversion layer (Figure 2). Thus, the part of the plume which is above the inversion height is supposed to be trapped there and cannot re-enter the boundary layer. Overlooking this phenomenon can lead to false estimations of the ground concentration, either by overestimating concentrations if the plume is always trapped below the inversion layer, or by underestimation if the plume is trapped above the inversion layer. A partial penetration of the plume is therefore assumed when the plume centerline (after plume rise) is close enough to the inversion height. The formulae come from Hanna and Paine (1989). If the plume rise $\Delta h$ exceeds $\left(z_{i}-z_{s}\right) / 1.5$, the top of the plume impacts the capping inversion, and a partial or total penetration of the inversion layer occurs. The fraction of the plume that has penetrated the inversion layer, called the penetration factor, is equal to $P=1.5-\Delta z / \Delta h$ if $0.5<\Delta z / \Delta h<1.5$ (partial penetration), and $P=1$ if $\Delta z / \Delta h \leq 0.5$ (total penetration), where $\Delta z=z_{i}-z_{s}$. In the case of a partial penetration, the fraction of the plume that remains within the boundary layer has a new emission rate $Q(1-P)$ and a new value of plume rise $\Delta h^{\prime}=(0.62+0.38 P)\left(z_{i}-z_{s}\right)$ (shown in Figure 2). In the case of a total penetration, the remaining emission rate is equal to zero and there is no plume left in the boundary layer. 


\section{Comparison of the dispersion formulae}

a. Comparison set-up

The evolution of the Gaussian standard deviations (without a possible additional spread due to the diameter and/or plume rise) can be plotted for the parameterizations described in the previous section, in order to evaluate the spread. It must be noted that the Briggs formulae give $\sigma_{y}$ and $\sigma_{z}$ as a function of the downwind distance $x$ from the source, whereas the Doury and similarity-theory parameterizations are expressed according to the travel time $t$. These two parameters are related through $t=x / u$, with $u$ the wind speed. The evolution of the standard deviations against $t$ is given in Figure 3. The Briggs formulae are computed for the six Pasquill stability classes, taking a wind speed value representative of the stability

class: $u=2 \mathrm{~m} \mathrm{~s}^{-1}$ for A and F classes, $u=2.5 \mathrm{~m} \mathrm{~s}^{-1}$ for B, $u=4 \mathrm{~m} \mathrm{~s}^{-1}$ for $\mathrm{C}, u=5.5 \mathrm{~m} \mathrm{~s}^{-1}$ for $\mathrm{D}$ and $u=3 \mathrm{~m} \mathrm{~s}^{-1}$ for $\mathrm{E}$ class. To compute the standard deviations with similarity theory, some other meteorological data is needed, and the following values are taken: the friction velocity $u_{*}=0.3 \mathrm{~m} \mathrm{~s}^{-1}$, the boundary layer height $h=500 \mathrm{~m}$. The Monin-Obukhov length $L$ is computed according to the relationship between $L$ and the roughness length $z_{0}$ given by Golder (1972), taking the roughness value for Prairie Grass $z_{0}=0.01 \mathrm{~m}$. This leads to the value for unstable cases (corresponding to B class) $L=-5.86 \mathrm{~m}$, and for stable cases (E class) $L=11.5 \mathrm{~m}$. The convective velocity is computed with the formula $w_{*}^{3}=-u_{*}^{3} h /(0.4 L)$. The plume height is taken at $z=1.5 \mathrm{~m}$. 


\section{b. Evaluation of the standard deviations}

Figure 3(a) shows the evolution of the horizontal standard deviations up to about three hours. The values for $\sigma_{y}$ at $t=9000 \mathrm{~s}$ range from $100 \mathrm{~m}$ (similarity theory) to $3000 \mathrm{~m}$ (Doury) in stable cases. In unstable cases, there is less variability, since $\sigma_{y}$ ranges from $1200 \mathrm{~m}$ to $3000 \mathrm{~m}$. The standard deviation computed with similarity theory is the smallest in stable and neutral cases, but it compares to the Briggs results in unstable cases. The Doury standard deviations are comparable to the others in unstable cases, and the largest in the case of stable situations. For larger travel times, it would grow above all other parameterizations. Also, if the wind speed is very low (about $0.5 \mathrm{~m} \mathrm{~s}^{-1}$ ), the downwind distance remains relatively small even for large travel times, therefore the Doury and similarity-theory parameterizations give larger standard deviations at a given distance than Briggs's. The spread for the vertical standard deviation is also very large (Figure $3(\mathrm{~b})$ ). In stable cases $\sigma_{z}$ values range from about $20 \mathrm{~m}$ (similarity theory) to $400 \mathrm{~m}$ (Doury). In unstable cases, there are larger differences, with $\sigma_{z}$ ranging from $100 \mathrm{~m}$ (similarity theory) to $3500 \mathrm{~m}$ (Briggs, class A), so over 30 times larger. Of all parameterizations, only the Briggs formulae for the unstable classes A, B and C show standard deviations above $500 \mathrm{~m}$. Similarity theory is the parameterization giving the smallest vertical standard deviation for all stabilities.

These preliminary results highlight a large variability in the standard deviations, depending on the stability and the parameterization. Thus, a substantial variability can also be expected in the output results. Besides, because of the differences in estimations of $\sigma_{z}$,

the plume might penetrate the inversion layer with some parameterizations and not with others, which would increase the variability. It should also be pointed out that the stabil- 
ity diagnosis depends on the standard deviation formula used. For instance, in the Prairie Grass experiments, the Pasquill-Turner diagnosis used with the Briggs formulae considers $30 \%$ of the experiments to be unstable, $20 \%$ stable and $50 \%$ neutral, whereas the diagnosis based on Monin-Obukhov length (Table 8) - used for similarity theory-gives about $48 \%$ of unstable cases and $52 \%$ of stable cases. This might compensate some of the differences in the standard-deviation estimations: for instance, similarity theory in unstable cases and Briggs's formulae in neutral cases give similar estimations.

\section{Evaluation with Prairie Grass experiment}

a. Model evaluation criteria

The statistical evaluation method is used for all models in this comparison, and described in Chang and Hanna (2004). It is also the method used in the Model Validation Kit (Olesen and Chang 2005), which has been developed and tested during a series of workshops and conferences on Harmonization within Atmospheric Dispersion Modeling for Regulatory purpose. In many field experiments, the sensors are placed in arcs at various distances downwind of the source, and the maximum predicted and observed concentrations for each arc ("maximum arcwise concentrations") are compared. Therefore, all other concentration values on the arc are not used in the comparison. The maximum observed value is determined on timeaveraged concentration measurements (the averaging time for Prairie Grass experiments is 10 minutes). The comparison study is carried out using maximum arcwise concentrations normalized by the emission rate $Q$ - so-called "centerline values" - in $\mu g m^{-3} /\left(g s^{-1}\right)$. 
The results are discussed using scatter diagrams as well as statistical performance measures such as the fractional bias (FB), the normalized mean square error (NMSE), the fraction of predictions within a factor two of observations (FAC2) and the correlation coefficient (Corr). The formulae to compute these statistics are given in Appendix 8. It should be noted that these formulae give negative values of $\mathrm{FB}$ for model overprediction and positive values if the model tends to underpredict concentrations. A perfect model would have Corr and $\mathrm{FAC} 2$ equal to 1.0 and $\mathrm{FB}$ and NMSE equal to 0.0. As there is no such thing as a perfect model, it is useful to determine typical performance measures for acceptable models. Those criteria have been summarized in Chang and Hanna (2004) and in Hanna et al. (2004) based on the evaluation of many models with many field datasets. A model is deemed acceptable if the mean bias is within $\pm 30 \%$ of the mean $(-0.3 \leq \mathrm{FB} \leq 0.3)$, if the random scatter is about a factor of two to three of the mean $(\mathrm{NMSE} \leq 4)$, and if the fraction of predictions within a factor two of the observations is about $50 \%$ (FAC2 $\geq 0.5)$.

\section{b. Experiment and modeling set-up}

The Prairie Grass experiment has become a standard database on which parameterizations have been fitted, and has been used for many model-evaluation studies. The experiment took place in O'Neil, Nebraska, during summer 1956. The site was a flat terrain of short cut grass. A continuous plume of $\mathrm{SO}_{2}$ was released, without plume rise, near the ground (at $0.46 \mathrm{~m}$ ). Measurements were taken on five arcs at 50, 100, 200, 400 and $800 \mathrm{~m}$ from the

source. A set of 43 of the 68 trials is usually used for model validations, including a wide range of stability conditions during day and night. In our simulations, the stability classes 
are taken from the database used in Hanna et al. (2004) for FLACS evaluation, and the other experimental data are taken from the US EPA (Environmental Protection Agency) database (http://www.epa.gov/scram001/dispersion_prefrec.htm).

c. Comparison with other Gaussian models

Many Gaussian models and a few CFD models were evaluated with Prairie Grass experiment. Three of the most used Gaussian models were compared in CERC (2007): ISCST3 and AERMOD are recommended by the US EPA, and ADMS4 is developed in the UK and widely used in Europe. ISCST uses discrete categories to describe the atmospheric stability (Pasquill-Guifford parameterization for rural areas and Briggs's formulae for urban area), whereas AERMOD and ADMS use boundary layer depth and Monin-Obukhov length to describe the state of the atmospheric boundary layer. The CFD models FLACS (FLame ACceleration Simulator) (Hanna et al. 2004), and Mercure (Demaël and Carissimo 2008) were also evaluated using Prairie Grass data.

Table 1 shows the Prairie Grass statistics for Polyphemus plume model with several parameterizations, along with the aforementioned Gaussian models. Results for ADMS4, AERMOD and ISCST3 come from (CERC 2007). The statistics for these three models are computed with a subset from the usual set of 43 experiments (used for Polyphemus evaluation), hence the differences in the mean observed centerline values. The statistics presented here are computed for the centerlines of the five arcs. Most values in Table 1 are within the acceptable range defined in Section a. AERMOD, ISCST3 and Polyphemus with the Briggs formulae show good results, as expected since the parameterizations they use for 
standard deviations are fitted on Prairie Grass experiment. On the contrary, the results for Polyphemus with Doury's formula and ADMS4 are hardly within the range of acceptable model performance for all indicators: ADMS4 underpredicts the mean concentrations by about $30 \%$, and only $29 \%$ of the values predicted by the Doury model are within a factor two of the observations. Polyphemus with similarity theory shows very good results - there is almost no bias, and the correlation and NMSE are the best of all models presented here. A more detailed analysis of the results with Polyphemus Gaussian models is provided below.

\section{d. Statistics for each arc}

The model performance is now analyzed for the five monitoring arcs, so as to compare the behavior of the three standard-deviation parameterizations. Figure 4 shows the statistical indicators, described in Section a, computed on the centerline values for each arc separately, for the 43 experiments. The "acceptable range" as defined in Section a is delimited by the dashed lines. Most indicators show a decreasing performance at farther distances from the source, except the correlation. Whereas Briggs's and Doury's parameterizations underpredict the concentrations - this tendency increases with the distance (FB grows higher) - similarity theory overpredicts the concentrations, especially at the farthest arcs (400 m and $800 \mathrm{~m})$. This can be related to the small standard deviation values given by this parameterization, pointed out in Section 3. At the first two arcs $(50 \mathrm{~m}$ and $100 \mathrm{~m})$, similarity theory gives the best results for all indicators. Finally, the Doury parameterization shows a poor performance in terms of FAC2, as well as for NMSE and FB, for all distances. In comparison to these results, the FLACS results reported in Hanna et al. (2004) underestimated the concentra- 
tions at the shortest distances (up to $200 \mathrm{~m}$ ), and slightly overpredicted the results at the farthest arcs. Demaël and Carissimo (2008) also found the underestimation tendency for Mercure CFD model at short distances. They attributed it to the Eulerian dispersion which corresponds to a plume behavior in $\sigma \propto \sqrt{t}$ (with $t$ the travel time) whereas the plume dispersion at short range should be in $\sigma \propto t$. For C, D and E stability classes, the overall performance of the Mercure CFD model was shown to be between that of the Briggs and Doury parameterizations.

Figure 5 shows the scatter plots for the three parameterizations. While the behavior of the model with the Briggs parameterization is quite well fitted with the observations, the overprediction tendency at the two further arcs is clearly shown for similarity theory. The scatter plot for the Doury parameterization confirms its poor performance especially in term of FAC2: the results for one arc are almost flat, which means that the modeled concentrations at one arc do not vary much with the different experiments. This could come from the representation of the atmosphere stability in only two classes (normal and low diffusion) which may be insufficient in some meteorological situations. Section 3 also showed that the Doury parameterization can give a very high value of $\sigma_{y}$ compared to the other two parameterizations at a given distance, especially at low wind speeds. 


\section{Evaluation with Kincaid experiment}

\section{a. Experiment and modeling set-up}

The Kincaid experiment took place at the Kincaid power plant in Illinois (USA) in 1980 and 1981. The plant stack is $187 \mathrm{~m}$ high with a diameter of 9 meters and is surrounded by flat farmland and some lakes. Meteorological data came from an instrumented tower, and the conditions during the experiments ranged from neutral to convective. The tracer material was a buoyant plume of $\mathrm{SF}_{6}$ gas, released from the stack and measured by monitors deployed on arcs between 0.5 and $50 \mathrm{~km}$ from the source at ground level. There were 200 monitors that were shifted day-to-day to correspond to the wind direction, and the arcs distances also varied with the meteorological situation. The recorded measurements are the arc maximum concentrations averaged over 1 hour. The database contains 171 hours of measurements. This dataset is often used to validate plume rise parameterizations because of the highly buoyant release that led to substantial plume rise. All data used for the following simulations is given with the Model Validation Kit (http://www.harmo.org/kit/ Download.asp). In this dataset, a quality indicator was assigned to each measurement value, denoting how reliable the maximum concentration should be considered (Olesen 1995). Only the most reliable data, of quality 2 and 3, were used here. The statistics are computed on 165 experiments.

It has to be pointed out that in the following study, the simulations with Polyphemus Gaussian model use the observed inversion height when available and, for some cases, the predicted height. On the contrary, other models presented here like ADMS, AERMOD, and most likely OML and HPDM, recomputed the inversion height with their own preprocessor. 
This could lead to significant differences, since this height is of great importance to know whether the plume touches the ground or is trapped above the inversion layer, as explained in Section 2. Simulations were carried out with three parameterizations for standard deviations (similarity-theory, Briggs's and Doury's) and three parameterizations for plume rise described in Section 2. The chimney diameter as well as the initial plume spread due to plume rise were taken into account in the total standard deviations (Equation 2). When similarity theory is used, the alternative HPDM formulae for elevated release detailed in Appendix 7 are used. Compared to the usual similarity-theory parameterization, it slightly increases the overestimation but it also improves the correlation coefficient, especially with Briggs-HPDM plume rise. The model evaluation consists, first, in comparing the results with the different parameterizations, with an emphasis on the plume rise description. In a second part, we compare the results with those of other models.

\section{b. Model evaluation}

\section{1) Plume RISE}

A first analysis of the plume rise values is done in this section, so as to compare the plume rise formulations and to give an insight on the additional variability due to plume rise. Figure 6 shows the plume rise values computed with the three parameterizations and 165 experiments, against the wind speed. As expected, the plume rise decreases with higher wind speeds, smoothing discrepancies between the different schemes. It was pointed out, for example in Canepa et al. (2000), that the Briggs scheme has a tendency to overestimate plume rise at low wind speeds. Indeed, the plume rise given by the Briggs-HPDM scheme 
reaches very high values for low wind speeds. The Holland and Concawe plume rises are similar, which is not surprising considering that the former was used in the design of the latter. Hence, we can suppose that the model behavior will be similar for those two schemes, whereas using Briggs-HPDM could lead to a model underestimation, if the plume is predicted to be too high. In addition, Table 2 shows the proportion of cases in Kincaid experiments with total or partial penetration in the inversion layer: as expected, it is higher for BriggsHPDM plume rise, with almost $60 \%$ of the cases. The Holland and Concawe plume rises give about the same number of cases with total penetration. However, there are less cases with partial penetration given by Holland than by Concawe formulae.

Hereafter, evaluation results are analyzed for each of the three plume-rise parameterizations (statistics on all arcs and experiments). For each plume rise parameterization, the scheme for standard deviations which performs best is in bold in the tables. The similaritytheory parameterization is labeled "Sim.th.".

\section{2) Results with BRIgGs-HPDM Plume Rise}

Table 3 shows the model results with Briggs-HPDM plume rise, for the three standarddeviation schemes. As expected, the tendency is to underpredict the concentrations, by a factor of two for the Briggs formulae and three for the Doury formulae. On the contrary, the similarity-theory parameterization performs quite well for all indicators (since there is nearly no bias), except for the correlation, which is quite low for all standard deviations.

This is confirmed by Figure 7 where the scatter plot for the Briggs formulae clearly indicates the underestimation tendency (Figure 7(b)), whereas the one with similarity theory 
(Figure 7(a)) is much more centered. However, in both cases, one can observe "vanishing concentrations" - concentrations that are observed but are not reproduced by the model. This can occur when the plume rise is too high, if the plume totally penetrates the inversion layer, or if it touches the ground later than the observed plume. In the first case, simulated concentrations are equal to zero at all arcs for the experiment, since there is no re-entering of the plume below the inversion layer. In the second case, only the concentrations at the nearest arcs to the source are missing, that is, the highest concentrations. This phenomenon could be responsible for the low correlations that are globally observed.

\section{3) Results with Holland plume Rise}

Results with Holland plume rise are given in Table 4. The modeled concentrations are globally higher than with the HPDM plume rise, since the estimated plume rise is lower. However, the Doury parameterization still underestimates considerably the concentrations, as with the Prairie Grass experiment. The bias and NMSE are considerably improved for the Briggs parameterization whereas the concentrations overestimation with similarity theory has increased, leading to a higher bias and NMSE than with HPDM plume rise.

The "vanishing concentrations" can be seen for the scatter plots of all plume rise parameterizations (not shown here), not only for Briggs-HPDM. Hence, one cannot point out that a particular scheme overestimates the plume rise, and this may also come from an inaccurate estimation of the observed boundary layer height. 


\section{4) Results with Concawe plume Rise}

Here, the best results are given by the Briggs parameterization, as in the case of the Holland formulae. For the Briggs-HPDM plume rise, the best results were with similarity theory. As expected, the results with Concawe plume rise are not very different from the Holland results, especially when looking at the mean concentrations and the biases. However, the correlation and the proportion of values within a factor two of the observation have increased. This slightly better performance is not surprising, considering that this formula was built from a set of different plume rise formulae, including Holland, and adjusted on a set of cases, especially neutral and convective cases with buoyant plumes, as explained in Brummage (1968).

\section{c. Comparison with other Gaussian models}

For this comparison, we use the results obtained with the Concawe parameterization which gives the best results for all standard-deviation formulae. In addition, the results with similarity theory and HPDM plume rise are also provided since they are good despite the lower correlation. Results for the other models come from CERC (2007), as in the case of Prairie Grass, for quality 2 and 3 (Table 6). As noted in Section a, we used 165 experiments instead of 171, hence the slight differences in the observed mean and standard deviations. Results with Polyphemus models are between those of AERMOD and ADMS4, except for the correlations that are lower as already observed, and comparable to these of ISCST3.

Using data of quality 3 only, we can also compare with HPDM (USA, Hanna and Paine (1989)), OML (Denmark), SAFE_AIR (Italy, Canepa et al. (2000)), as well as the Lagrangian 
model NAME (UK, Webster and Thomson (2002)). The statistics for HPDM and OML come originally from Olesen (1995). Table 7 shows the results for all these models. ISCST3, AERMOD and Polyphemus with the Doury formulae show a significant underestimation of the mean values, hence the high bias and NMSE. All other models slightly underestimate the mean values except SAFE_AIR and Polyphemus with similarity theory and Concawe plume rise which slightly overpredicts the observations. The correlation results are surprisingly against this trend: for instance, AERMOD has a correlation of $40 \%$ which is comparable to the best results. On the contrary, models that have an otherwise good performance such as SAFE_AIR, OML, and Polyphemus models with Concawe formulae have relatively low correlations. The correlation for Polyphemus with similarity theory and HPDM plume rise is very low $(5 \%)$ but this configuration is among the best models for all other indicators. This correlation is not surprising since the HPDM model evaluation in Hanna and Paine (1989) also showed low correlations with this experiment. Further improvements were made in HPDM, such as a correction to take into account the plume lofting at the inversion layer during convective conditions, and this seems to have greatly improved the results. Table 7 also shows that the spread in the model outputs is very large: the predicted mean concentrations range from about $20 \mathrm{ng} \mathrm{m}^{-3} / \mathrm{g} \mathrm{s}^{-1}$ to $70 \mathrm{ng} \mathrm{m}^{-3} / \mathrm{g} \mathrm{s}^{-1}$, which means more than a factor of 3 between some models. It is interesting to note that, with the different parameterizations available in Polyphemus for standard deviations and plume rise, we can reproduce the same spread, the model configuration being otherwise unchanged. Only the correlations are still low, no matter the formula used, which tends to prove that it comes from the shared inversion-height modeling (plume penetration and lofting). 


\section{Conclusion}

Polyphemus Gaussian plume and puff models were described, with an emphasis on the parameterizations used to estimate the standard deviations and the plume rise. The Gaussian plume model was then used to compare these various parameterizations within a single framework, all other model features being equal. A preliminary study on the standard deviation values (Section 3) highlighted a large variability: the estimated values could differ from up to a factor 30. Although the variability of the estimated plume rise is not so high, except for low wind speeds (Section 5), it produces an additional variability in the output results, especially since the plume might penetrate the inversion layer or not, depending on the parameterization.

The model evaluation against Prairie Grass and Kincaid experiments gave very satisfactory overall results, compared to other well-known Gaussian models. Similarity theory is the best standard-deviation scheme, which is not surprising since it relies on a more detailed description of the atmosphere. However, the Briggs formulae also compare well with other model results, not only with Prairie Grass experiment - on which they were adjusted — but also with Kincaid. Only the Doury parameterization appears to be unsatisfactory for the two experiments used here, since it tends to overestimate the plume spread, leading to underestimation of the concentrations. There is no striking difference in performance-for these cases - between "old generation" schemes, based on a discrete representation of the stability (Briggs, Pasquill-Guifford used in ISCST3) and the "new generation" estimations based on similarity theory, although the latter performs slightly better.

The results with Kincaid experiment point out the additional variability due to plume 
rise estimation. In particular, the "best" standard-deviation parameterization depends on the plume rise scheme used (similarity theory with Briggs-HPDM plume rise, and Briggs's standard deviations with Concawe and Holland formulae). All combinations perform well, except with the Doury formulae. The results also highlight the importance of some features such as a non-Gaussian shape for convective conditions, as well as plume lofting at the inversion layer. These missing features are most likely responsible for the relatively low correlations. A meteorological preprocessor that would recompute the inversion height could also help improving the results for Kincaid experiment.

With three parameterizations to compute the standard deviations, and the same number of plume rise schemes, we were able to show a large spread in the model outputs, representative of the variability of the Gaussian models. The main perspective is now to extend that work in order to include more parameterizations and to compare with more datasets, providing a full comparison between parameterizations in the same conditions. This study also suggests that ensemble modeling with Gaussian models could be interesting in the future.

\section{APPENDIX}

\section{Formulae for standard deviations with similarity the-}

\section{ory}

In all the formulae presented here, the stability is determined from the Monin-Obukhov length, as given in Table 8, which also shows the corresponding Pasquill class. 
a. Within the boundary layer

\section{1) TRAnSVERSE SPREAD $\sigma_{y}$}

First, we have to determine the horizontal standard deviation of wind velocity fluctuations $\sigma_{v}$. For that part we use formulae given in Hanna et al. (1982).

$$
\begin{aligned}
& \sigma_{v}=\quad u_{*}\left(12-0.5 \frac{h}{L}\right)^{1 / 3} \quad \text { unstable } \\
& \sigma_{v}=\quad 1.3 u_{*} \exp \left(-2 \frac{f z}{u_{*}}\right) \quad \text { neutral } \\
& \sigma_{v}=\max \left(1.3 u_{*}\left(1-\frac{z}{h}\right), 0.2\right) \quad \text { stable }
\end{aligned}
$$

where $h$ is the boundary layer height, $L$ is the Monin-Obukhov length, $f$ is the Coriolis parameter and $z$ is the height where concentrations are computed.

The function $F_{y}$ is given by the general form

$$
F_{y}=\left(1+0.5 \frac{t}{\tau_{L}}\right)^{-1 / 2}
$$

where $\tau_{L}$ is the Lagrangian time scale. To compute this parameter, we use formulae given in Hanna (1984).

$$
\begin{array}{lll}
\tau_{L}= & 0.15 \frac{h}{\sigma_{v}} & \text { unstable } \\
\tau_{L}= & 0.5 \frac{z}{\sigma_{v}} /\left[1+15 \frac{f z}{u_{*}}\right] & \text { neutral } \\
\tau_{L}= & 0.07 \frac{h}{\sigma_{v}} \sqrt{\frac{z}{h}} & \text { stable }
\end{array}
$$

where $h$ is the boundary layer height, $L$ is the Monin-Obukhov length, $u_{*}$ is the friction velocity, $f$ is the Coriolis parameter and $z$ is the height where concentrations are computed. 


\section{2) Vertical SPREAD $\sigma_{z}$}

The vertical wind standard deviation is computed using formulae given in Venkatram et al. (1984) for stable and neutral cases and in Weil (1988) for convective cases.

$$
\begin{array}{ccc}
\sigma_{w}= & 0.6 w_{*} & \text { unstable } \\
\sigma_{w}=1.3 u_{*}\left(1-\frac{z}{h}\right)^{3 / 4} & \text { stable/neutral }
\end{array}
$$

where $w_{*}$ is the convective velocity, $u_{*}$ is the friction velocity, $h$ the boundary layer height and $L$ the Monin-Obukhov length.

The function $F_{z}$ is given by Irwin (1979) for stable and neutral case and by Weil (1988) for convective cases.

- Unstable cases:

$$
F_{z}=\left(1+0.5 \frac{t}{\tau_{L z}}\right)^{-1 / 2}
$$

- Stable/Neutral cases:

$$
F_{z}= \begin{cases}{\left[1+0.9\left(\frac{t}{50}\right)\right]^{-1}} & \text { if } z<50 \\ {\left[1+0.945(0.1 t)^{0.806}\right]^{-1}} & \text { if } z \geq 50\end{cases}
$$

where $h$ is the boundary layer height, $L$ is the Monin-Obukhov length, $z$ is the height where concentrations are computed. The following expression is advocated by Hanna et al. (1982) for the vertical Lagrangian time scale $\tau_{L z}$ :

$$
\begin{array}{rll}
\tau_{L z}= & 0.15 h \frac{1-\exp \left(-5 \frac{z}{h}\right)}{\sigma_{w}} & \text { unstable } \\
\tau_{L z}=0.5 \frac{z}{\sigma_{w}} /\left[1+15 \frac{f z}{u_{*}}\right] & \text { neutral } \\
\tau_{L z}= & 0.10 \frac{h}{\sigma_{w}}\left(\frac{z}{h}\right)^{0.8} & \text { stable }
\end{array}
$$




\section{b. Alternative formulae for elevated sources}

In Hanna and Paine (1989), an alternative set of formulae is proposed for sources of height greater than $100 \mathrm{~m}$, since the other formulations based on similarity theory were calibrated on experiments closer to the ground and did not give satisfactory results in the case of the Kincaid experiment, for instance. These formulae are used for stable or neutral cases, where dispersion was found to be greater than given by the classical formulation.

- The wind vertical standard deviation is computed as:

$$
\begin{array}{ccc}
\sigma_{w}= & 0.5 \sqrt{1.2 u_{*}^{2}+0.35 w_{*}^{2}} & L \geq 100 \\
\sigma_{w}= & 1.3 u_{*} & 0 \leq L<100
\end{array}
$$

- The wind horizontal standard deviation is computed as:

$$
\begin{array}{ccc}
\sigma_{v}= & 0.7 \sqrt{3.6 u_{*}^{2}+0.35 w_{*}^{2}} & L \geq 100 \\
\sigma_{v}=\max \left(1.5 \sqrt{3.6 u_{*}^{2}+0.35 w_{*}^{2}}, 0.5\right) & 0 \leq L<100
\end{array}
$$

For the vertical standard deviation, the function $F_{z}$ does not change, but the vertical time scale is computed with a different set of formulae for stable and slightly unstable cases. In the following formulae, $s_{p}$ stands for the Briggs static stability parameter defined in Section 2.

- In the case of stable/neutral situations $(L>0$.):

$$
\begin{aligned}
& \tau_{L z}=\quad z / \sigma_{w} \quad \text { if } z \leq L \\
& \tau_{L z}=\quad 0.27 \sqrt{s_{p}} \quad \text { if } L \leq 10 \\
& \tau_{L z}=\left(z / \sigma_{w}\right)(L-10) /(z-10)+0.27 \sqrt{s_{p}}(z-L) /(z-10) \text { if } 10<L<z
\end{aligned}
$$

- In the case of slightly unstable situations $(|L| \leq 100)$ :

$$
\tau_{L z}=0.27\left(z / \sigma_{w}\right)(0.55-0.38 z /|L|) \quad \text { if } z \leq|L|
$$




$$
\tau_{L z}=0.3\left(h / \sigma_{w}\right)(1-\exp (-5 z / h)-0.0003 \exp (8 z / h)) \quad \text { if }|L|<z<h
$$

c. Above the boundary layer

\section{1) HPDM FORMULAE FOR WIND STANDARD DEVIATIONS}

All the formulae given by similarity theory are valid only within the boundary layer. There are not many studies about the dispersion above the boundary layer, so the formulae used for that case are quite simple. They come from Hanna and Paine (1989).

$$
\begin{aligned}
\sigma_{v} & =0.1 \sqrt{3.6 u_{*}^{2}+0.35 w_{*}^{2}} \\
\sigma_{w} & =0.1 \sqrt{1.2 u_{*}^{2}+0.35 w_{*}^{2}}
\end{aligned}
$$

They are applied for all stabilities. They ensure that the dispersion parameters at least are always strictly positive values (no division by zero or square root of a negative value...). However, since in most case studies the observed concentrations are inside the boundary layer, and there is no mixing through the inversion layer, these are not the most used formulae in practice.

\section{2) Gillani formula for Vertical Standard DeViation}

An alternative way to compute $\sigma_{z}$ above the boundary layer is given by Gillani and Godowitch (1999):

$$
\sigma_{z}^{2}=\sigma_{z_{\mathrm{pr}}}^{2}(1+2.3 \sqrt{t})
$$

assuming that $t$ is the time travel of the plume, as usual, and the initial time is equal to 0. One can note that this formula can be applied above the boundary layer for all parameterizations. The initial plume spread $\sigma_{z_{\mathrm{pr}}}$ due to plume rise is computed differently from the formula given in Section 2 since the initial spread is often overestimated that way. An alternative way proposed by 
Gillani and Godowitch (1999) is:

$$
\sigma_{z_{\mathrm{pr}}}=\max (15 \exp (-117 d T / d z), 3)
$$

where $d T / d z$ is the vertical ambient temperature gradient.

\section{Statistical indicators}

$$
\begin{gathered}
\mathrm{FB}=\frac{\left(\bar{C}_{0}-\bar{C}_{p}\right)}{0.5\left(\bar{C}_{0}+\bar{C}_{p}\right)} \\
\mathrm{NMSE}=\frac{\overline{\left(C_{0}-C_{p}\right)^{2}}}{\bar{C}_{0} \bar{C}_{p}} \\
\mathrm{Corr}=\frac{\overline{\left(C_{0}-\bar{C}_{0}\right)\left(C_{p}-\bar{C}_{p}\right)}}{\sigma_{C_{0}} \sigma_{C_{p}}}
\end{gathered}
$$

$\mathrm{FAC} 2=$ fraction of data that satisfies $0.5 \leqslant \frac{C_{p}}{C_{0}} \leqslant 2.0$

where $C_{p}$ and $C_{0}$ are the predicted and measured maximum arcwise concentrations respectively,

$\bar{\alpha}$ is the average of value $\alpha$ over the dataset (that is, for all experiments and arcs), and $\sigma_{\alpha}$ is the standard deviation over the dataset.

\section{REFERENCES}

Arya, S., 1999: Air pollution meteorology and dispersion. Oxford University press. 
Briggs, G., 1971: Some recent analyses of plume rise observations. Proceedings of the Second International Clean Air Congress, Englund, H.M. and Berry, W.T., Ed., Academic Press, New York, $1029-1032$.

Brummage, K. G., 1968: The calculation of atmospheric dispersion from a stack. Atmos. Env., 2, 197-224, stichting Concawe study.

Canepa, E., L. Dallorto, and C. Ratto, 2000: About the plume rise description in the dispersion code SAFE_AIR. Int. J. Env. and Pollution, 14 (1-6), 235-245.

CERC, 2007: ADMS4 Flat terrain validation: Kincaid, Indianapolis and Prairie Grass. Tech. rep., Cambridge Environmental Research Consultants. 15 pp.

Chang, J. and S. Hanna, 2004: Air quality model performance evaluation. Meteorology and Atmospheric Physics, 87, 167-196.

Demaël, E. and B. Carissimo, 2008: Comparative evaluation of an eulerian CFD and gaussian plume models based on prairie grass dispersion experiment. J. Applied Meteor., 47 (3), 888-900.

Doury, A., 1976: Une méthode de calcul pratique et générale pour la prévision numérique des pollutions véhiculées par l'atmosphère. Tech. Rep. 4280, CEA, France.

Gillani, N. and J. Godowitch, 1999: Plume-in-grid treatment of major point source emissions. Science algorithms of the EPA models-3 Community Multi-scale Air Quality (CMAQ) modeling system, D. Byun and J. Ching, Eds., EPA, chap. 9, 9.1-9.37.

Golder, D., 1972: Relations among stability parameters in the surface layer. Boundary-Layer Meteor., 3, 47-58. 
Hanna, S., 1984: Applications in air pollution modeling. Atmospheric turbulence and Air Pollution modeling, F. Niewstadt and H. van Dop, Eds., D. Reidel Publishing Co., 275-309.

Hanna, S., G. Briggs, and R. Hosker Jr., 1982: Handbook on atmospheric diffusion. Technical Information center, US Department of energy.

Hanna, S., O. Hansen, and S. Dharmavaram, 2004: FLACS CFD air quality model performance evaluation with Kit Fox, MUST, Prairie Grass, and EMU observations. Atmos. Env., 38, 46754687.

Hanna, S. and R. Paine, 1989: Hybrid plume dispersion model (HPDM) development and evaluation. J. Applied Meteor., 28, 206-224.

Holland, J. Z., 1953: A meteorological survey of the oak ridge area. Tech. Rep. ORO-99, US AEC, Oak Ridge, Tennessee.

Irwin, J., 1979: Scheme for estimating dispersion parameters as a function of release height. Tech. Rep. 600:4-79-062, US EPA. 26 pp.

Mallet, V., et al., 2007: Technical Note: The air quality modeling system Polyphemus. Atmos. Chem. Phys., 7 (20), 5479-5487.

Olesen, H., 1995: The model validation exercise at mol: overview of results. Int. J. Env. and Pollution, 5 (4-6), 761-784.

Olesen, H. and J. Chang, 2005: Consolidating tools for model evaluation. Proceedings of the 10th international conference on Harmonisation within Atmospheric Dispersion Modelling for Regulatory Purposes, Sissi, Crete, 263-267. 
Pasquill, F., 1961: The estimation of the dispersion of windborne material. Meteorol. Mag., 90 (1063), 33-49.

Seinfeld, J. H. and S. N. Pandis, 1998: Atmospheric chemistry and physics: from air pollution to climate change. Wiley-Interscience.

Stümke, H., 1963: Vorschlag einer empirischen Formel für die Schornsteinüberhöhung. Staub, 23, 549.

Turner, D. B., 1969: Workbook of atmospheric diffusion estimates. Tech. Rep. 999-AP-26, US EPA, Washington, DC.

Venkatram, A., D. Strimaitis, and D. Cicristofaro, 1984: A semiempirical model to estimate dispersion of elevated releases in the stable boundary layer. Atmos. Env., 18, 923-928.

Webster, H. and D. Thomson, 2002: Validation of a lagrangian model plume rise scheme using the kincaid data set. Atmos. Env., 36 (1-6), 5031-5042.

Weil, J., 1988: Dispersion in the convective boundary layer. Lectures on Air Pollution modeling, A. Venkatram and J. Wyngaard, Eds., American Meteorological Society. 


\section{List of Tables}

1 Statistics for several Gaussian models: comparison of maximum arc concentration for simulation and observation. Polyphemus results are presented for three formulae for standard deviations and 43 trials in Prairie Grass Experiment.

2 Proportion of cases with total or partial penetration in the inversion layer for all three plume rise parameterizations. Proportion with respect to 165 experiments.

3 Statistics for Polyphemus Gaussian models: comparison of centerline values $C / Q$ for simulations and observations - Kincaid data of quality 2 and 3. There are 165 experiments. Unit is $n g m^{-3} /\left(g s^{-1}\right)$. Plume rise is computed with Briggs-HPDM formulae.

4 Statistics for Polyphemus Gaussian models: comparison of centerline values $C / Q$ for simulations and observations - Kincaid data of quality 2 and 3. There are 165 experiments. Unit is $n g m^{-3} /\left(g s^{-1}\right)$. Plume rise is computed with Holland formulae. 38

5 Statistics for Polyphemus Gaussian models: comparison of centerline values $C / Q$ for simulations and observations - Kincaid data of quality 2 and 3. There are 165 experiments. Unit is $n g m^{-3} /\left(g s^{-1}\right)$. Plume rise is computed with Concawe formulae. 39

6 Statistics for several Gaussian models: comparison of centerline values $C / Q$ for simulations and observations - Kincaid data of quality 2 and 3. Unit is $n g m^{-3} /\left(g s^{-1}\right) .40$

7 Statistics for several Gaussian models: comparison of centerline values $C / Q$ for simulation and observation - Kincaid data of quality 3. Unit is $n g m^{-3} /\left(g s^{-1}\right)$.

8 Matching between Monin-Obukhov length and stability, from Seinfeld and Pandis (1998). 


\begin{tabular}{lccccc}
\hline Model & Mean & FB & NMSE & Corr & FAC2 \\
\hline Observations & 2.23 & 0.00 & 0.00 & 1.00 & 1.00 \\
ADMS4 & 1.56 & 0.36 & 3.01 & 0.63 & 0.66 \\
AERMOD & 2.14 & 0.04 & 1.83 & 0.75 & 0.73 \\
ISCST3 & 2.01 & 0.11 & 1.78 & 0.72 & 0.61 \\
\hline Observations & 2.32 & 0.00 & 0.00 & 1.00 & 1.00 \\
Briggs & 2.33 & 0.00 & 1.83 & 0.78 & 0.74 \\
Doury & 1.74 & 0.29 & 2.58 & 0.67 & 0.29 \\
Similarity theory & 2.34 & -0.01 & 0.91 & 0.85 & 0.62 \\
\hline
\end{tabular}

TABLE 1. Statistics for several Gaussian models: comparison of maximum arc concentration for simulation and observation. Polyphemus results are presented for three formulae for standard deviations and 43 trials in Prairie Grass Experiment. 


\begin{tabular}{ccc}
\hline Model & Total penetration & Partial penetration \\
\hline Briggs-HPDM & $29 \%$ & $28 \%$ \\
Holland & $23 \%$ & $17 \%$ \\
Concawe & $24 \%$ & $23 \%$ \\
\hline
\end{tabular}

TABLE 2. Proportion of cases with total or partial penetration in the inversion layer for all three plume rise parameterizations. Proportion with respect to 165 experiments. 


\begin{tabular}{ccccccc}
\hline Model & Mean & std & FB & NMSE & Corr & FAC2 \\
\hline Obs & 39.89 & 39.22 & 0.00 & 0.00 & 1.00 & 1.00 \\
\hline Briggs & 21.33 & 21.10 & 0.61 & 2.37 & 0.19 & 0.43 \\
Doury & 12.77 & 14.09 & 1.03 & 4.70 & 0.07 & 0.22 \\
Sim.th. & 42.02 & 34.73 & -0.05 & 1.33 & 0.19 & 0.45 \\
\hline
\end{tabular}

TABLE 3. Statistics for Polyphemus Gaussian models: comparison of centerline values $C / Q$ for simulations and observations - Kincaid data of quality 2 and 3. There are 165 experiments. Unit is $n g m^{-3} /\left(g^{-1}\right)$. Plume rise is computed with Briggs-HPDM formulae. 


\begin{tabular}{ccccccc}
\hline Model & Mean & std & FB & NMSE & Corr & FAC2 \\
\hline Obs & 39.89 & 39.22 & 0.00 & 0.00 & 1.00 & 1.00 \\
\hline Briggs & 33.01 & 28.26 & 0.19 & 1.46 & 0.21 & 0.42 \\
Doury & 15.87 & 13.27 & 0.86 & 3.55 & 0.04 & 0.28 \\
Sim.th. & 61.97 & 47.52 & -0.43 & 1.38 & 0.24 & 0.38 \\
\hline
\end{tabular}

TABLE 4. Statistics for Polyphemus Gaussian models: comparison of centerline values $C / Q$ for simulations and observations-Kincaid data of quality 2 and 3. There are 165 experiments. Unit is $n g m^{-3} /\left(g^{-1}\right)$. Plume rise is computed with Holland formulae. 


\begin{tabular}{ccccccc}
\hline Model & Mean & std & FB & NMSE & Corr & FAC2 \\
\hline Obs & 39.89 & 39.22 & 0.00 & 0.00 & 1.00 & 1.00 \\
\hline Briggs & 32.88 & 32.75 & 0.19 & 1.49 & 0.27 & 0.48 \\
Doury & 16.87 & 17.74 & 0.81 & 3.29 & 0.12 & 0.31 \\
Sim.th. & 61.82 & 53.79 & -0.43 & 1.57 & 0.24 & 0.43 \\
\hline
\end{tabular}

TABLE 5. Statistics for Polyphemus Gaussian models: comparison of centerline values $C / Q$ for simulations and observations-Kincaid data of quality 2 and 3. There are 165 experiments. Unit is $n g m^{-3} /\left(g s^{-1}\right)$. Plume rise is computed with Concawe formulae. 


\begin{tabular}{ccccccc}
\hline Model & Mean & std & FB & NMSE & Corr & FAC2 \\
\hline Obs & 41.0 & 39.3 & 0.00 & 0.00 & 1.00 & 1.00 \\
ADMS4 & 40.4 & 31.1 & -0.05 & 0.80 & 0.50 & 0.58 \\
AERMOD & 20.3 & 24.1 & 0.68 & 2.30 & 0.35 & 0.33 \\
ISCST3 & 23.1 & 53.3 & 0.56 & 3.83 & 0.26 & 0.26 \\
\hline Obs & 39.89 & 39.22 & 0.00 & 0.00 & 1.00 & 1.00 \\
Briggs/Concawe & 32.83 & 32.80 & 0.19 & 1.50 & 0.27 & 0.47 \\
Doury/Concawe & 16.75 & 17.81 & 0.82 & 3.32 & 0.12 & 0.30 \\
Sim.th./Concawe & 61.70 & 53.91 & -0.43 & 1.58 & 0.25 & 0.43 \\
Sim.th/HPDM & 41.99 & 34.76 & -0.05 & 1.33 & 0.19 & 0.44 \\
\hline
\end{tabular}

TABLE 6. Statistics for several Gaussian models: comparison of centerline values $C / Q$ for simulations and observations - Kincaid data of quality 2 and 3. Unit is $n g \mathrm{~m}^{-3} /\left(\mathrm{gs}^{-1}\right)$. 


\begin{tabular}{ccccccc}
\hline Model & Mean & std & FB & NMSE & Corr & FAC2 \\
\hline Obs & 54.34 & 40.25 & 0.00 & 0.00 & 1.00 & 1.00 \\
ADMS4 & 48.5 & 31.5 & 0.11 & 0.60 & 0.45 & 0.68 \\
AERMOD & 21.8 & 21.8 & 0.86 & 2.07 & 0.40 & 0.29 \\
ISCST3 & 30.0 & 60.0 & 0.57 & 2.80 & 0.26 & 0.28 \\
HPDM & 44.84 & 38.55 & 0.19 & 0.75 & 0.44 & 0.56 \\
SAFE_AIR & 59.73 & 52.54 & -0.09 & 1.10 & 0.20 & 0.50 \\
OML & 47.45 & 45.48 & 0.13 & 1.24 & 0.15 & 0.55 \\
NAME & 38.7 & 47.2 & 0.33 & 1.45 & 0.27 & 0.56 \\
\hline Obs & 53.69 & 40.72 & 0.00 & 0.00 & 1.00 & 1.00 \\
Briggs/Concawe & 37.95 & 33.06 & 0.34 & 1.20 & 0.21 & 0.58 \\
Doury/Concawe & 17.36 & 14.21 & 1.02 & 3.19 & 0.18 & 0.30 \\
Sim.th./Concawe & 68.91 & 51.25 & -0.25 & 1.03 & 0.17 & 0.58 \\
Sim.th/HPDM & 47.92 & 33.93 & 0.11 & 1.05 & 0.05 & 0.59 \\
\hline
\end{tabular}

TABLE 7. Statistics for several Gaussian models: comparison of centerline values $C / Q$ for simulation and observation-Kincaid data of quality 3. Unit is $n g m^{-3} /\left(g s^{-1}\right)$. 


\begin{tabular}{ccc}
\hline L: Monin-Obukhov length $(\mathrm{m})$ & Stability & Pasquill class \\
\hline$-100 \leq L<0$ & unstable & $\mathrm{B}$ \\
$-10^{5} \leq L<-100$ & unstable & $\mathrm{C}$ \\
$|L|>10^{5}$ & neutral & $\mathrm{D}$ \\
$10 \leq L<10^{5}$ & stable & $\mathrm{E}$ \\
$0 \leq L<10$ & stable & $\mathrm{F}$ \\
\hline
\end{tabular}

TABLE 8. Matching between Monin-Obukhov length and stability, from Seinfeld and Pandis (1998). 


\section{List of Figures}

1 Representation of an elevated source: $z_{s}$ is the source height and $z_{p}$ is the effective source height, with plume rise. The modeled point of emission is at $z_{p}$ but the downwind travel is neglected during plume rise. The initial plume spread due to plume rise is $\sigma_{z_{\mathrm{pr}}}$.

2 Partial penetration in the inversion layer: $z_{s}$ is the source height and $z_{i}$ is the inversion layer source height. The penetration factor is noted $P$. The initial plume rise is $\Delta h$ and the plume rise of the remnant part of the plume within the boundary layer is $\Delta h^{\prime}$. Finally, $Q$ is the total emission rate.

3 Evolution of the Gaussian standard deviations $\sigma_{y}$ and $\sigma_{z}$ against of the travel time from the source, for Briggs's formulae (six stability classes), Doury's parameterization (normal diffusion) and similarity-theory scheme (stable, neutral and unstable cases.

4 Evolution of the statistics against the downwind distance from source, for six statistical indicators and the three standard deviation parameterizations. The statistics are computed at five monitoring arcs $(50 \mathrm{~m}, 100 \mathrm{~m}, 200 \mathrm{~m}, 400 \mathrm{~m}$ and $800 \mathrm{~m}$ ). The acceptable performance is situated between the dashed lines.

5 Scatter plot of maximum arc concentrations for observations and simulations with various sigma parameterizations. Prairie Grass experiment, 43 trials. Unit is $\mu \mathrm{g} \mathrm{m}^{-3} /\left(\mathrm{g} \mathrm{s}^{-1}\right)$. The results are shown at five monitoring $\operatorname{arcs}(50 \mathrm{~m}, 100 \mathrm{~m}, 200 \mathrm{~m}$, $400 \mathrm{~m}$ and $800 \mathrm{~m})$. 
6 Plume rise (in $\mathrm{m}$ ) computed by the different schemes for Kincaid experiments, as a function of the wind speed.

7 Scatter plots of centerline values $C / Q$ for simulations and observations-Kincaid data of quality 2 and 3. There are 165 experiments. Unit is $n g m^{-3} /\left(g s^{-1}\right)$. Plume rise is computed with the Briggs-HPDM formulae. Standard deviations are computed with the Briggs and similarity-theory formulae. 


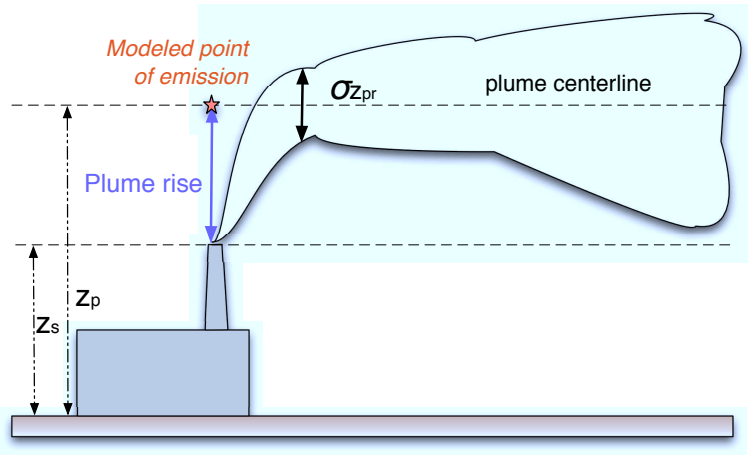

FIG. 1. Representation of an elevated source: $z_{s}$ is the source height and $z_{p}$ is the effective source height, with plume rise. The modeled point of emission is at $z_{p}$ but the downwind travel is neglected during plume rise. The initial plume spread due to plume rise is $\sigma_{z_{\mathrm{pr}}}$. 


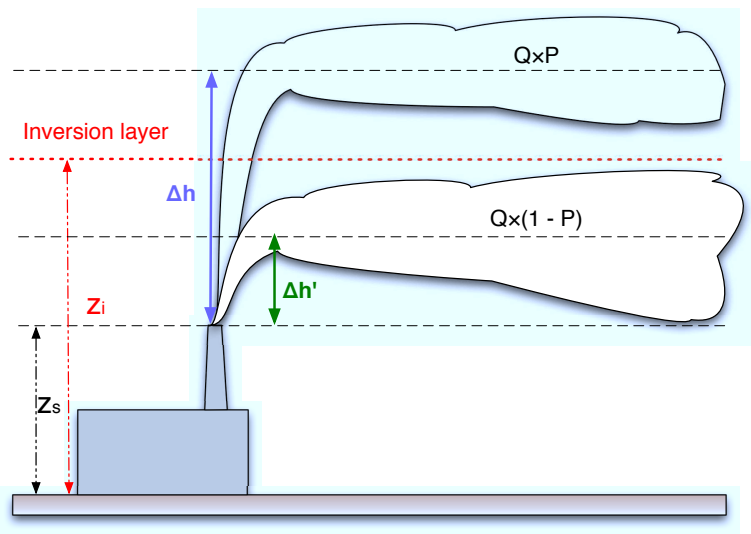

FIG. 2. Partial penetration in the inversion layer: $z_{s}$ is the source height and $z_{i}$ is the inversion layer source height. The penetration factor is noted $P$. The initial plume rise is $\Delta h$ and the plume rise of the remnant part of the plume within the boundary layer is $\Delta h^{\prime}$. Finally, $Q$ is the total emission rate. 


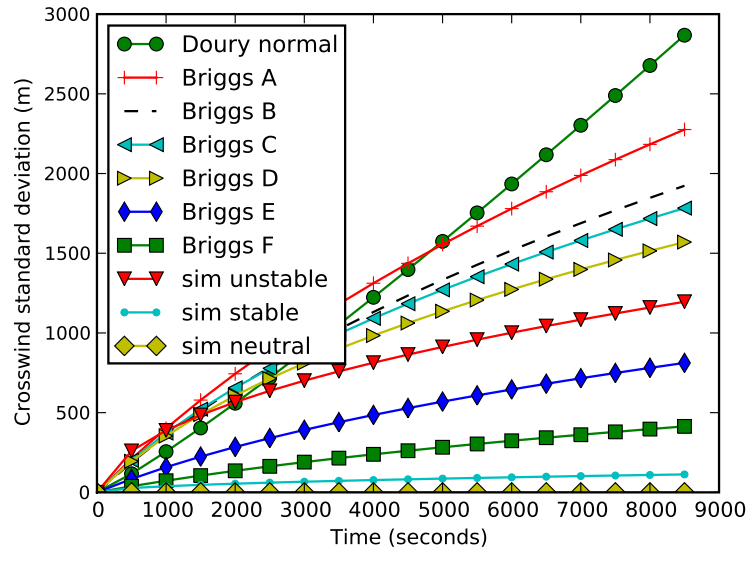

(a) Horizontal standard deviation

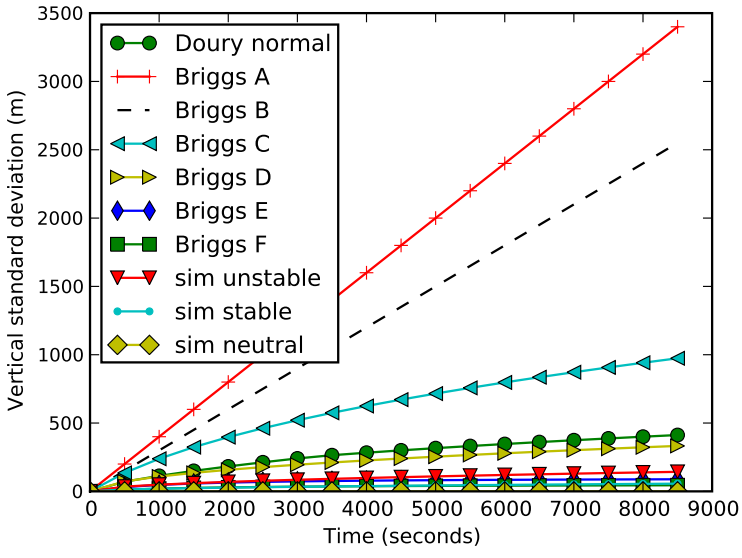

(b) Vertical standard deviation

FIG. 3. Evolution of the Gaussian standard deviations $\sigma_{y}$ and $\sigma_{z}$ against of the travel time from the source, for Briggs's formulae (six stability classes), Doury's parameterization (normal diffusion) and similarity-theory scheme (stable, neutral and unstable cases. 

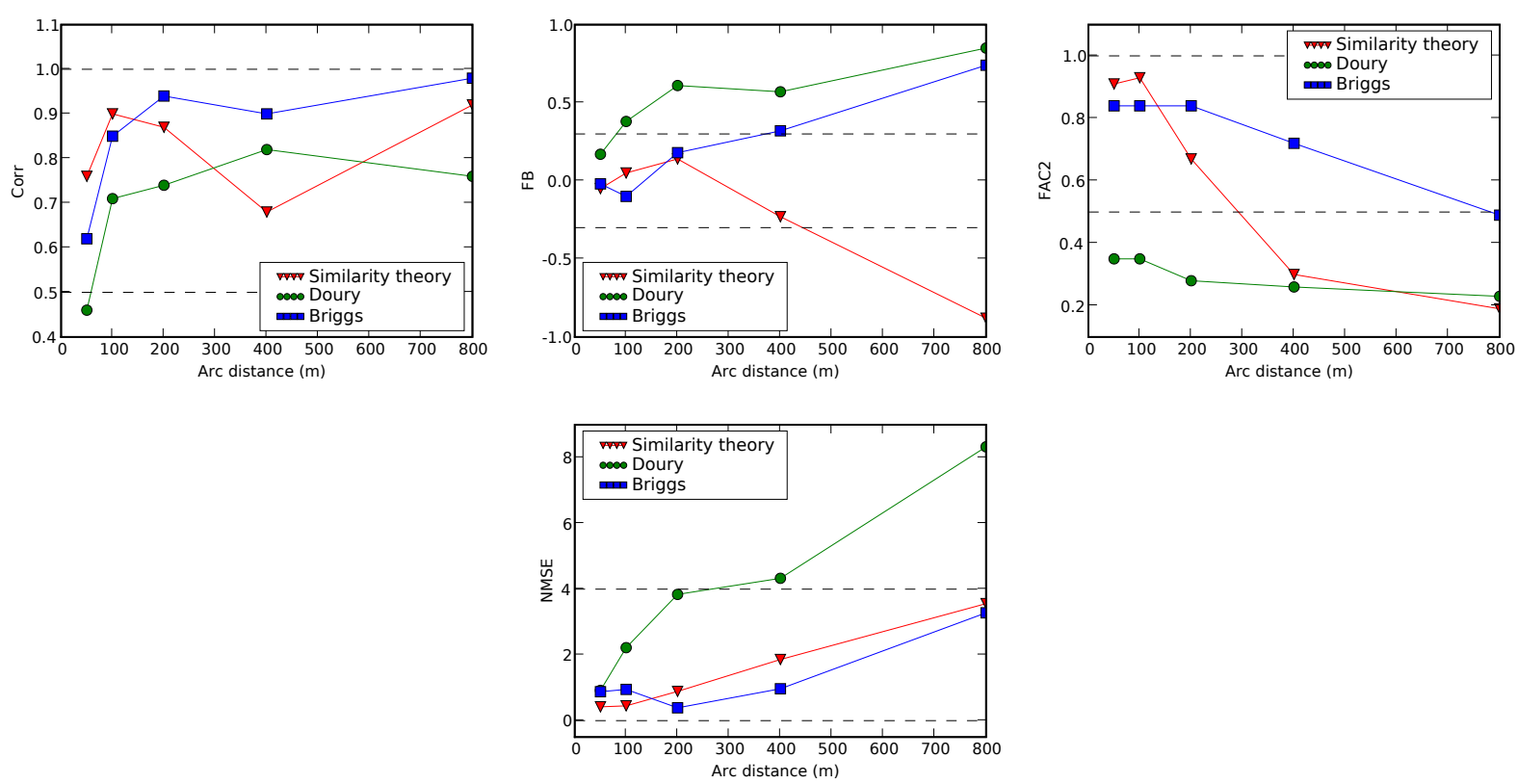

FIG. 4. Evolution of the statistics against the downwind distance from source, for six statistical indicators and the three standard deviation parameterizations. The statistics are computed at five monitoring arcs $(50 \mathrm{~m}, 100 \mathrm{~m}, 200 \mathrm{~m}, 400 \mathrm{~m}$ and $800 \mathrm{~m})$. The acceptable performance is situated between the dashed lines. 


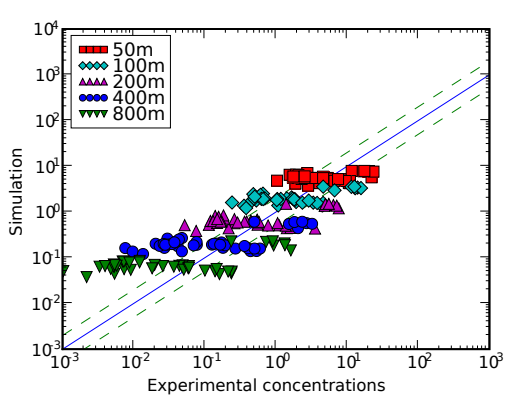

(a) Doury parameterization

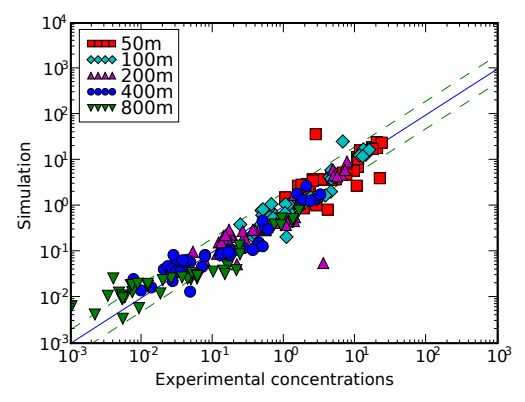

(b) Briggs parameterization

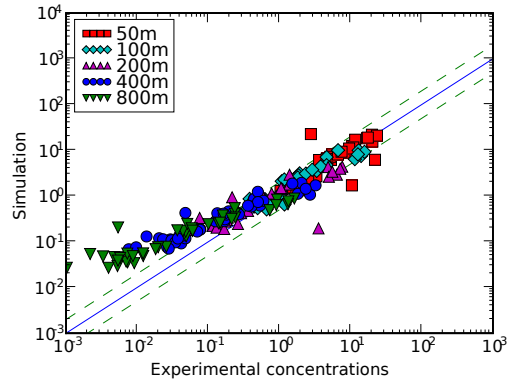

(c) Similarity theory

FIG. 5. Scatter plot of maximum arc concentrations for observations and simulations with various sigma parameterizations. Prairie Grass experiment, 43 trials. Unit is $\mu g \mathrm{~m}^{-3} /\left(\mathrm{g} \mathrm{s}^{-1}\right)$. The results are shown at five monitoring arcs $(50 \mathrm{~m}, 100 \mathrm{~m}, 200 \mathrm{~m}, 400 \mathrm{~m}$ and $800 \mathrm{~m})$. 


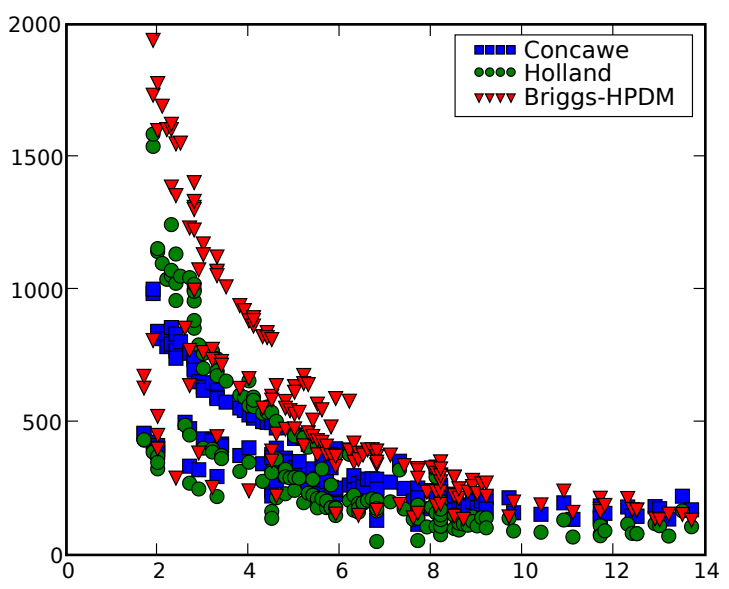

FIG. 6. Plume rise (in m) computed by the different schemes for Kincaid experiments, as a function of the wind speed. 


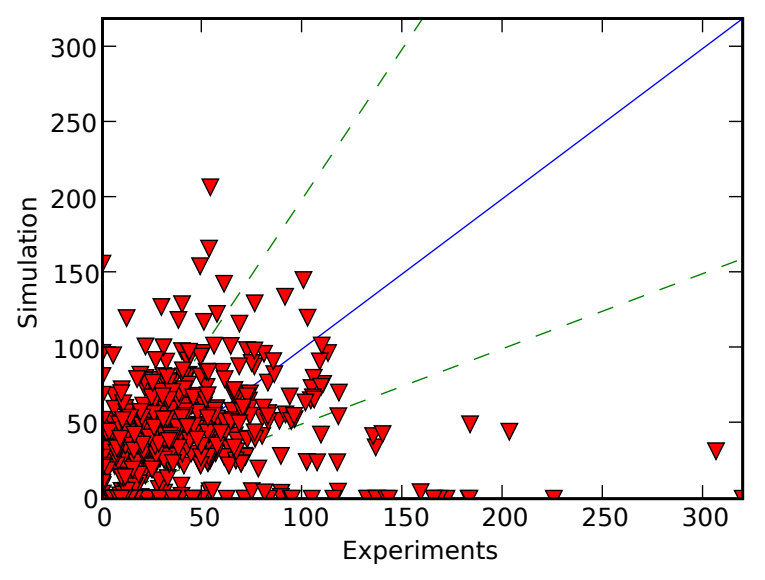

(a) Similarity theory

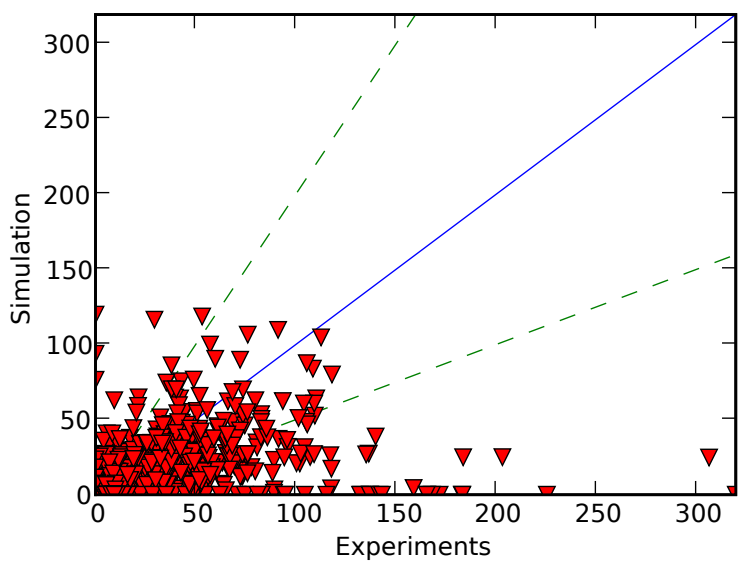

(b) Briggs

FiG. 7. Scatter plots of centerline values $C / Q$ for simulations and observations-Kincaid data of quality 2 and 3. There are 165 experiments. Unit is $n g m^{-3} /\left(g^{-1}\right)$. Plume rise is computed with the Briggs-HPDM formulae. Standard deviations are computed with the Briggs and similaritytheory formulae. 